\title{
Pension Scheme Deficits
}

\section{Steven Hull (ed.)}

\author{
Globe Law and Business, 2007, ISBN 190578308 6, 273pp (www.gblawbooks.com)
}

Pensions (2008) 13, 121-122. doi:10.1057/pm.2008.4

By the time a title has been conceived, a publisher found, the pages written, the edited masterpiece sent to the printer, the publicity issued and the warehouse committed, time has often rendered the point of the book otiose.

The skilled and able team, lead by Steven Hull as editor, which put this wonderful book together must have had second thoughts along the way as press reports emerged about the return to financial health of the UK pensions movement following the depressing bear markets of 2000-2003.

But their faith in the project has been justified by the efforts of regulators who have determined in the last few years to make a recovering situation worse. So partly because of increasingly perverse accounting rules, the inability of obesity to rein back the galloping longevity increases, and the capture of investment fashions such as LDI by the regulatory industry, pension funds are as much in deficit as ever they were.

Accordingly there is much to write about. And this book certainly covers the subject. Jonathan Seres provides a succinct and despairing litany of how it is that a pensions sector once so flourishing and emblematic of the common sense of the British has fallen on hard times, not so much because of change of circumstance (although may have played a part) but because of misplaced regulatory enthusiasm. Stephen Yeo, a master of the political infighting in Westminster that has lead to the state we are in, describes how we fixed all these problems in the old days, by using actuarial sleight of hand and masterly inactivity.
Further sections outline how employers, trustees and advisors can try to slice off at least part of the deficits by scheme benefit changes (Camilla Berry), changes to accrual arrangements to for example career average (Danny Tsang) or defined contribution (Gary Smith), or asking members to leave (Ian Gault and Susanne Wilkins).

And there are easy to understand practical and commercial outlines of how escrow accounts (Mark Alexander, Julian Jones) and other contingent assets (Mark Catchpole) work. All these chapters are short, easy to read, highly practical and nicely balanced, and they are prepared by practitioners from leading law firms and actuarial firms.

Also covered are employment law considerations, communications and the souldestroying impact of the regulatory framework. Andrew Powell writes a dry and neutral description of the procedures to be followed, and a subsequent chapter on how to put a scheme into the PPF when appropriate details the administration operations to be followed. These chapters are useful and provide a handy starting point for practitioners, but they somehow lack the critical overview of the earlier part of the work, which made such a refreshing read. In particular, they expect somewhat optimistically that regulators and others will behave proportionately and commercially when required to do so, an approach not always experienced so far in practice.

A generic outline of the buy-out market provides an engaging summary of what is a fast 
moving area, and inevitably dating by the day, but it does explain some of the thinking of sometimes creative financial engineers, determined to take the pensions off the balance sheet, while placating the regulators and protecting the members. Separate chapters cover trustee liability, independent trustees (inevitably partisan) and overseas practice in Canada, Germany, Ireland and the States.

Overlooking a lack of balance in one or two of the chapters, this is a book the authors, and in particular the editor (who unusually did not write any of the sections and who has managed to infuse the book with a coherent structure, a consistent style and eminent practicality), can be proud of, as can the publishers. The care taken in its writing and editing has also flowed through to the sometimes lost art of book production. The volume is a joy to handle, is nicely set on good paper, strongly bound and elegantly designed. Someone has loved this book and it shows. And despite the best efforts of investment managers, and the reduction in the numbers of defined benefit pension schemes, deficits are going to be with us yet awhile, which means this book seems destined to have a long and distinguished future in print.

Robin Ellison

E-mail: Robin.Ellison@pinsentmasons.com 